\title{
La didáctica de la traducción poética en el EEES
}

\author{
JESÚS BELOTTO \\ Universidad de Alicante \\ jesus.belotto@ua.es
}

Recibido: 30 de noviembre de 2012

Aceptado: 27 de febrero de 2013

\section{RESUMEN}

El objetivo del presente artículo es destacar puntos fuertes y retos en la mejora de la didáctica de la traducción poética a partir de una valoración crítica de las metodologías y recursos empleados por los docentes con el objetivo de establecer las bases para desarrollar propuestas concretas para la enseñanza de esta disciplina, sus posibilidades y sus limitaciones en el marco del EEES, incidiendo en la importancia de la automatización de principios metodológicos y estrategias en la práctica de traducción de textos de función estética y tratando de colegir el interés de aquellas competencias que podrán desarrollar en este tipo de materias los traductores que entren en el mercado de otra especialidad.

Palabras clave: didáctica, traducción, literatura, poesía.

Poetry Translation Didactics in the EHEA

\begin{abstract}
This paper aims to offer an overview of the situation of poetry translation didactics where strengths can be highlighted, together with the challenges still to be met in this particular field of study. First of all, I will try to elaborate a critical analysis of methodologies and teaching resources, aiming to set the foundations for the development of specific teaching proposals for Poetry Translation in the context of the European Higher Education Area and reflecting on the potentialities and limitations of such proposals and on the interest to be raised in other areas of the translation professional market by the competencies acquired by students in these courses.
\end{abstract}

Keywords: didactics, translation, literature, poetry.

Sumario: 1. Introducción. 2. La traducción poética en la universidad española. 3. Apuntes sobre la enseñanza actual de la traducción poética. 4. La enseñanza de la traducción poética 
como lectura. 5. Algunas propuestas en la enseñanza de la lectura. 6. A modo de conclusión. 7. Referencias bibliográficas.

\section{Introducción}

El principal objetivo del presente artículo es proponer una reflexión sobre la realidad actual de la traducción poética en las aulas y los retos que plantea su enseñanza. Para ello, describiremos someramente la situación de la traducción literaria en licenciatura y en grado; a continuación, trataremos de interrogar la validez de algunos de los conceptos más arraigados en torno a esta disciplina en relación con las necesidades que el futuro profesional o practicante de la traducción poética/literaria habrá de experimentar, tras lo cual glosaremos nuestra propia concepción de la traducción poética como lectura; terminaremos planteando algunas propuestas didácticas generales que puedan inscribirse en el marco del EEES. Teniendo en cuenta la infinitud del abanico textual que abarca este campo, incidiremos en la importancia de dirigir las miras hacia una metodología que no se circunscriba a la detección y resolución de lo que ha dado en llamarse "problemas" de traducción, siempre más o menos puntuales, sino en aguijar la creatividad del futuro traductor y su gusto por la materia, facilitando además al alumno su familiarización con el panorama literario contemporáneo y con las herramientas mediáticas de que puede disponer para escrutar la situación del mismo a cada momento.

\section{La traducción poética en la universidad española}

Hasta la llegada del EEES, la Licenciatura en Traducción e Interpretación en la Universidad de Alicante constaba de 300 créditos, 14 de los cuales correspondían obligatoriamente a materias de traducción literaria: Introducción a la traducción literaria ( $8 \mathrm{cr}$.) y Traducción literaria ( $6 \mathrm{cr}$.). A estos, el alumno podía sumar hasta otros 12 de los 24 dedicados a materias optativas, a saber: Traducción literaria II, principalmente práctica, y Teoría de la traducción literaria, totalmente teórica, a razón de 6 créditos cada una. Además, el alumno tenía a disposición 30 créditos de libre elección que podía emplear, caso de estar interesado en ello, en cursar otras materias en relación con el ámbito literario de las distintas carreras de filología de la UA o de cualquier otra universidad española o europea, caso de disfrutar de una beca Séneca o Erasmus. Esto significa que un alumno convencido de querer dedicarse a la traducción literaria y profesiones aledañas podía cursar hasta 56 créditos (casi un quinto de la titulación) sólo en especializarse en ello. La entrada en vigor en nuestro país del llamado plan Bolonia y la consiguiente conversión de la licenciatura en grado ha supuesto una reducción de créditos que afecta a casi todas las especialidades de traducción, pero con especial fuerza a la literaria: los 300 créditos del título son ahora 240, y el grado cuenta con una asignatura de Traducción literaria en tercer curso (6 cr.) y una optativa en cuarto, Traducción literaria avanzada, 
también de 6 créditos, por lo que ahora el alumno podrá cursar entre 6 y 12 créditos. En porcentajes, entre un 2,5 y un $5 \%$ de la carga lectiva total.

Sea como fuere, los 56 créditos de licenciatura que podían dedicarse exclusivamente a la literatura y su traducción se mostraban más que insuficientes de no continuar el alumno esta formación con algún postgrado, pero lo que las cifras anteriormente expuestas dejan claro es que con la licenciatura el alumno tenía la opción de emplear gran parte de sus horas lectivas en orientarse hacia la traducción literaria, mientras que los alumnos de grado no tendrán dicha posibilidad si no se matriculan en uno de los cada vez más costosos másteres dedicados a la traducción literaria. De hecho, ni siquiera pensamos que con entre 6 y 12 créditos el alumno pueda hacerse una idea real del mundo de la traducción literaria que le permita afianzar o desechar la "fantasía" de dedicarse a este tipo de traducción con la que, según Olivia de Miguel (cfr. Pino 2004. 34), se matriculan en la carrera la mayoría de alumnos.

En cualquier caso, al margen de sus difíciles posibilidades profesionales, tanto los docentes que se dedican a la enseñanza de la traducción literaria como los del resto de especialidades deben tener presente la importancia de un campo en el que el alumno va a "encontrarse con todos los posibles problemas que pueden surgir en cualquier otro tipo de traducción", en palabras de Natalia Arregui (2007: 151), y que nosotros pensamos que se da con más razón en el caso concreto de la traducción poética.

\section{Apuntes sobre la enseñanza actual de la traducción poética}

En un periodo tan crítico para la educación como el actual, el profesorado debe replantearse toda una serie de perversiones lingüísticas, academicismos e ideas precocinadas que puedan provocar que las pocas ocasiones que tengan de abordar en clase la poesía y su traducción se conviertan en motivo de indigestión para los alumnos. Para empezar, no podemos hablar de "objetivismo" en un campo, el poético, cuya principal característica es la "subjetivización" de un discurso que experimentará además la adscripción de un nuevo sujeto en el proceso de traducción. Gérard Dessons \& Henri Meschonnic (1998: 188) hablaban en este sentido del poema como "texto-sujeto" y de su receptor como "lector-sujeto". Además, consideramos la objetividad como perteneciente, el mismo término lo indica, a los objetos, lo que revela una cosificación de la poesía en el poema que falsea la actividad del traductor poético. Al traducir una sentencia de divorcio, el traductor jurado no traduce un texto sobre el divorcio, sino el propio divorcio; del mismo modo, el traductor de poesía reescribe un poema para traducir lo que este hace (y no lo que dice), su efecto: la poesía. Sea como fuere, en el estudio de la literatura y su traducción, la pretendida objetividad en cuanto a juicios de valor difícilmente puede ser sino una suma lo más numerosa posible de subjetividades coincidentes; "humanidades, ciencias en deseo", que diría Dámaso Alonso (1981: 397). Lo que no quiere decir que no tengamos presente, con los traslatólogos Reiss \& Vermeer (1996: 147), que "la inevitable subjetividad [...] no implica arbitrariedad". 
Las palabras más repetidas en los textos sobre didáctica de la traducción que hemos consultado son "problema", "dificultad", "restricción", "limitación" y otros descorazonadores sinónimos, y lo cierto es que no parece de gran ayuda la costumbre por parte de la crítica universitaria de presentar el poema como un problema y el producto de la traducción como una "solución" (Verdegal Cerezo 1996: 215). Ambos conceptos son erróneos, desde el momento en que ni el poema ni el producto de su traducción (que debe ser otro poema) pueden constituirse en respuestas, sino que, más bien al contrario, "la poésie existe comme sujet d'interrogation" (Espitallier 2009: 12), aspira a formular preguntas que quizá no sepamos (no podamos) expresar de otro modo, "la conciencia de algo de lo que no podemos tener conciencia de ninguna otra manera" . De este modo, la traducción poética debe aspirar a reformular dichas preguntas, y en ningún caso a responderlas, a solucionarlas, por no mencionar que el carácter definitivo que reviste la palabra "solución" no se corresponde con la realidad de la infinitud del poema original y la posibilidad de su retraducción.

Otras colocaciones recurrentes del tipo meterse en la piel del autor, como si de la camisa que mudara una serpiente se tratara, impregnarse del texto o identificar su tejido metafórico, son precisamente metáforas que, amén de viscosas, resultan a nuestro juicio tan vacías como el propio pellejo del autor-serpiente. Y eso por no hablar de las clasificaciones puntuales a las que numerosos autores se entregan en sus obras, atomizando las diversas tipologías o procesos de traducción e introduciendo una terminología que a menudo resulta vacua o contradictoria; contraproducente, en cualquier caso. Y es que, ¿qué puede significar que un texto se ha traducido palabra por palabra? ¿Alguien conoce, para la cabalística, algún texto traducido con el mismo número de palabras que el texto original? Y ¿quién decide que la traducción literal de un soneto alejandrino rimado es un soneto en verso libre blanco? ¿Acaso dicho texto original no está compuesto literalmente en un metro regular con un determinado tipo de repetición fónica a final de verso?

Una de las nociones más perniciosas para la traducción poética es la de "equivalencia", por más que esta pueda ser, en la terminología nidiana, "dinámica". Poco importa cuánto maticemos el significado de dicha equivalencia: esta obsesión por exigir al traductor-poeta un texto cuyo valor sea igual al del original implica abocarlo irremediablemente al papel del falsificador que anhela sustituir con su copia el original. $\mathrm{Si}$ una pieza del motor de nuestro coche se estropea y la sustituimos por otra diferente pero que cumple la misma función en las mismas condiciones, que hace que el motor funcione correctamente, podemos decir que es una pieza equivalente a la original, pero ninguna traducción puede sustituir al original, sobre todo porque no es ese el cometido de la traducción poética, que consiste a nuestro modo de ver en escribir un poema a partir de otro poema escrito en un lugar espacio-temporal distinto del nuestro.

"Nunca un consejo para ser feliz" es el título de un poema del poeta Ramón Rico Carpena que resulta adecuado para señalar un hecho que algunos profesores parecen

$1<$ http://la-convencion.blogspot.com.es/2012/03/entrevista-al-poeta-juan-carlos-mestre.html $>$ [Fecha de consulta: $12 / 04 / 2012]$. 
ignorar: las recomendaciones que hacemos a los estudiantes a partir de nuestra propia experiencia o de las teorías que manejamos a menudo se convierten en un arma de doble filo para el aprendiz de traductor de poesía. Los procedimientos que enseñamos a los alumnos deben ser guiados, sobre todo al principio, para que nuestros consejos no vayan en detrimento de su labor de traducción ni sirvan para perpetuar algunos de los prejuicios más perniciosos que han azotado secularmente nuestra disciplina. En no pocas ocasiones, el docente olvida advertir al alumnado acerca de las limitaciones de la documentación biográfica a propósito del autor, provocando interpretaciones que no siempre son acertadas o malentendidos como los que llevan a muchos alumnos a confundir al poeta con el yo poemático, esto es, a intercambiar sujeto real por sujeto textual, lo cual, sobre todo a partir de la modernidad decimonónica, resulta con frecuencia falaz. De igual modo, el análisis contrastivo de textos, que puede ser ilustrativo de la multiplicidad de posibilidades de traducción (insistimos: de lectura) que atesora el texto poético, da pie numerosas veces a tomar las diferencias entre original y traducción como errores o pruebas de la intraducibilidad de la poesía, cuando dichas diferencias son irremediables en tanto en cuanto al traductor no le es dado "reproducir exactamente las estructuras formales de un texto", lo que equivaldría no a traducir el texto sino a copiarlo, como bien apuntara Valentín García Yebra (cfr. Santoyo 1987: 325) en su Teoría y práctica de la traducción de 1982.

Pero no quisiéramos avanzar en nuestro razonamiento sin mencionar un hábito docente que siempre nos ha molestado: la tendencia a considerar el nivel de los alumnos desde la nostalgia del "cualquiera tiempo pasado" que conduce en mayor o menor medida a minusvalorar sus capacidades. Trabajando el soneto Le dormeur du val de Arthur Rimbaud en un grupo práctico de la asignatura Traducción literaria de III de Licenciatura, hicimos notar a los estudiantes que el mismo título del poema escondía un calambur que anunciaba ya el desarrollo de los catorce versos: la palabra "dormeur", a nivel fónico, contiene la tercera persona de los verbos "dormir" y "mourir", avanzando lo que efectivamente leeremos en el soneto; esto es, que el soldado tumbado en el valle parece dormir cuando en realidad, como el poema va sugiriendo y finalmente revela en la caída del último verso, está muerto. Cuál no sería nuestra sorpresa cuando, a la semana siguiente, nos topamos con el título de la traducción de la estudiante Valeria Gambi: "Desfallecido en el valle".

Esto nos permite señalar otra dicotomía impertinente: la que enfrenta el aprendizaje de la traducción de poesía con su realización mediante una cierta intuición o instinto. Pero tanto quienes enaltecen como quienes desprecian el valor de dicho instinto no reparan en que no se trata de un instinto natural, innato, sino que hablamos de una intuición que debemos adquirir mediante, precisamente, el estudio poético: la alumna de la que hablábamos más arriba ha necesitado creatividad y oído, pero nunca habría podido traducir el calambur rimbaldiano de no haber conocido de la existencia de esta suerte de frivolidades en la poesía de algunos autores. Es importante, pues, fomentar la curiosidad y la desconfianza del traductor para despertar en él una cierta conciencia socrática que le permita detectar por sí mismo este tipo de elementos "charged with meaning to the utmost possible degree", como definía Ezra Pound (cfr. Dessons \& Meschonnic 1998: 172) la gran literatura. Quien siembra dudas recoge (buenas) traducciones. 


\section{La enseñanza de la traducción poética como lectura}

A menudo, los profesores se han preguntado sobre la posibilidad o imposibilidad de enseñar a traducir poesía. La pregunta, a mi modo de ver, resulta tanto o más manida como la cuestión de si se puede o no traducir poesía. Si es posible aprender a traducir poesía, es posible enseñar a traducir poesía: mostrar, que no amaestrar, y prueba de ello la obtenemos planteándonos, como hacía el recientemente desaparecido Agustín García Calvo (cfr. Santoyo 1987: 282) en 1973 precisamente a propósito de la traducibilidad o no de la poesía, “¿cómo algo que se practica puede no ser posible?; ¿cómo lo que es de hecho no va a ser la demostración de su propia posibilidad?". Ante lógica tan aplastante, huelgan ulteriores digresiones; si bien se antoja de rigor apuntar que las fosas abisales de los estudios comparatistas (cfr. Hurtado Albir 1999: 18-19) y la sacralización del texto original que a menudo los ha acompañado han jugado un papel primordial en esta labor de descalificación de la traducción, sobre todo en el ámbito de la literatura en general y de la poesía en particular. Tampoco el prescriptivismo excluyente del que han adolecido la mayoría de reflexiones en torno a la traducción ha sido de gran ayuda en este aspecto.

Sin restar validez a lo anterior, podemos pensar con George Steiner que existan límites espacio-temporales a la traducción, de modo que a lo largo de la historia las posibilidades de traducción varíen: "No todo puede ser traducido [...]. No todo puede ser traducido ahora. Ciertos contextos desaparecen o se disipan los haces de referencias que en el pasado permitían interpretar un texto ahora opaco. Hemos perdido [...] la facultad de empatía retrospectiva" (cfr. Gallego Roca 1994: 39); y en sentido inverso, puede ocurrir que existan elementos cuya traducción o interpretación requiera de recursos a los que podamos tener acceso en un futuro. Un ejemplo paradigmático lo hallamos en el siguiente extracto del poema en prosa de Charles Baudelaire Le crépuscule du soir (la negrita es nuestra):

Le crépuscule excite les fous. - Je me souviens que j'ai eu deux amis que le crépuscule rendait tout malades. L'un méconnaissait alors tous les rapports d'amitié et de politesse, et maltraitait, comme un sauvage, le premier venu. Je l'ai vu jeter à la tête d'un maître d'hôtel un excellent poulet, dans lequel il croyait voir je ne sais quel insultant hiéroglyphe. Le soir, précurseur des voluptés profondes, lui gâtait les choses les plus succulentes.

La imagen de un loco golpeando a un camarero en la cabeza con un pollo asado porque, en su enajenación, cree que en la piel tostada de la suculenta ave hay grabados ofensivos lenguajes en clave ("hiéroglyphes" son también las manchas con formas que recuerdan a las letras en la cabeza de algunas serpientes) resulta tan cómica como verosímil, pero el sentido de la escena y sus implicaciones se multiplican exponencialmente cuando tenemos en cuenta, como señalaba en 1988 Jean Bellemin-Noël (cfr. Murphy 2007: 461-462), que entre las acepciones del vocablo "poulet" se encuentra la de un "billet" o "message", escrito además en un tipo de papel dorado, lo que acentúa la posible correspondencia con el color del volátil dorado al horno. Este flagrante caso de polisemia es tan difícil de detectar como de 
traducir, al menos si queremos mantener una ambigüedad que se ha perdido en todas y cada una de las numerosas traducciones existentes del poema hasta 2009, pero la evolución lingüístico-cultural del español ha propiciado la aparición de una expresión, "montar el/un pollo", o de una nueva acepción de la propia palabra "pollo" como "esputo", lo cual abre para un traductor imaginativo toda una serie de posibilidades de recreación del juego baudelairiano de las que un hispanohablante no disponía hace tan solo unas décadas.

Con Marco Borillo, Verdegal Cerezo y Hurtado Albir (1999: 170) coincidimos en que conviene enseñar al alumno a "buscar la versión definitiva desde el principio, evitando un borrador literal". Estos borradores en los que el alumno plasma únicamente el sentido lingüístico del original no sólo son innecesarios -un traductor que conoce la lengua y la cultura de origen puede, en la medida en que esto sea posible, entender el texto en su lengua y contexto originales sin necesidad de borradores literales-, sino que además pueden resultar funestos para la versión definitiva, ya que a menudo el alumno centra sus esfuerzos en la reescritura del borrador dejando de lado el texto original, con el alejamiento prematuro que esto supone y que provoca que la traducción se convierta no ya en una lectura o un conjunto de lecturas de un texto original, sino en una lectura o conjunto de lecturas sobre una primera lectura sesgada del original.

Así, dado el limitadísimo margen docente de que disponen los profesores de traducción literaria en los actuales planes de estudios, proponemos agrupar las competencias que se pretende que adquieran los alumnos en torno a la profundización de un conocimiento que estimamos primordial para el traductor de poesía: la competencia lectora. Y esto parece plausible porque, como trataremos de explicar a continuación, consideramos la traducción como un tipo de lectura, acaso "la lectura más perfecta que de [una obra] se pueda hacer", en palabras del ya no tan novísimo Luis Antonio de Villena (cfr. Morcillo 2009: 100).

El punto de vista que aquí defendemos resulta cercano al de Olivia de Miguel cuando dice que "los alumnos deben adiestrarse en la lectura, la interpretación, el debate, la escritura de su propia lengua. Esos son los ámbitos en los que habría que insistir" (cfr. Pino 2004: 24), sólo que nosotros entendemos todas las actividades en torno a un texto por traducir (comentario crítico, comprensión, reescritura...) como tipologías de lecturas del mismo. Así, lejos de ser "el primer paso", en la traducción de un poema todo, proceso y producto, es lectura; un estuario de lecturas sepultadas, presentes y sucesivas, parafraseando al poeta brasileño Lêdo Ivo (2009: 174). Lecturas supeditadas a un lector que es a su vez un cúmulo de sedimentos textuales de recepciones anteriores, según opinión de Roland Barthes (cfr. Moya 2004: 148): "ese yo que se aproxima al texto es ya una pluralidad de otros textos, de códigos infinitos, o más exactamente perdidos".

En su artículo "La poesía lírica", publicado en 1976 en la Revista de Occidente, José María Aguirre (cfr. Santoyo 1987: 294) señalaba el hecho mismo de la recepción de la poesía como un fenómeno de interpretación: "El poema es un problema. La solución encontrada por el lector no pasa de ser más que una interpretación de la fórmula. Leer es interpretar". De este modo, al margen del par problema-solución que hemos contestado en el anterior punto, la posibilidad de la traducción como 
nosotros la planteamos pasa por la posibilidad de una metalectura, de una lectura de lecturas; en definitiva, de que el traductor pueda ser, como ya sugería Novalis (cfr. Vega 1994: 218) en 1798, "el poeta del poeta".

Por otro lado, preocuparse como traductor por la función o el receptor de un texto no es sino desarrollar una conciencia de lector; más aún, de lector de lecturas, de metalector: si entendemos la interpretación de un texto como una posibilidad de lectura, entonces el traductor habrá de tratar siempre de "llegar a comprender el texto" (Arregui 2007: 151) no ya en el sentido de aprehenderlo intelectivamente, sino en el de abarcarlo; esto es, ser consciente de la posibilidad de acometer el poema como un abanico de posibles lecturas, máxime en aquellos casos en los que la polisemia sea parte constituyente de las particularidades del texto.

Evidentemente, el aprendizaje de la lectura requiere de un acompañamiento teórico, en la conciencia siempre de que no es la práctica la que debe amoldarse a la teoría, como parecía sugerir la profesora Arregui (2007: 157) al explicar una experiencia docente propia: "Llegados a este punto, [...] conocíamos la teoría y habíamos insertado el texto en el molde que habíamos creado". Sea como fuere, la reflexión que ha de acompañar a toda actividad universitaria debe, en el caso de la traducción de poesía, atreverse a formular aquellas preguntas para las que, sabemos, no existe (una) respuesta; la poesía y su traducción, ¿qué, por qué y para qué? Preguntas que, permítasenos insistir, son un fin en sí mismo para el ámbito que nos ocupa, y que no deben olvidar que la traducción poética, como la poesía, debe ser, lato sensu, una actividad moral, política. El profesor Terry Eagleton (2010: 26) acusa al (des)orden en el que (mal)vivimos inmersos como causante de la pérdida de sensibilidad social ante el lenguaje:

Lo que amenaza con desbaratar la sensibilidad verbal es el mundo sin profundidad, mercantilizado e instantáneamente legible del capitalismo avanzado, con su desaprensiva forma de tratar los signos, la comunicación computarizada y su rutilante empaquetamiento de la "experiencia".

Paradójicamente o no, esto sucede, no lo olvidemos, en el momento de la historia en el que más se escribe en todo el mundo; gracias al aumento de la alfabetización a nivel mundial, pero sobre todo gracias a la democratización (en el sentido más pobre de la palabra) de los medios de expresión y comunicación virtuales. La velocidad a la que leemos y escribimos, la inmediatez en la recepción textual impide al humano del s. XXI ir más allá de la superficie de las cosas, de las personas como cosas, nos impide sentir siquiera la necesidad de profundizar. $Y$ es en este sentido en el que la poesía se opone diametralmente al vertiginoso consumismo informativo actual: "Atender a la forma y textura de las palabras implica el rechazo a considerarlas meramente desde una perspectiva instrumental, y por tanto el rechazo a un mundo en el que el lenguaje se desgasta hasta ser más débil que el papel por efecto del comercio y la burocracia" (Eagleton 2010: 18).

Volviendo a la enseñanza de la traducción poética, dice Amalia Rodríguez que a "lo único que se puede enseñar es a leer" (cfr. Pino 2004: 34), pero, más que una consecuencia de la poca relevancia que se da a la traducción poética en los estudios 
actuales, esto quizá se deba al carácter inasible de la poesía, a la infinitud de un género textual que se caracteriza precisamente por su carencia de fronteras más allá de la osadía, imaginación y necesidad expresiva de los poetas. Cada texto supondrá pues para el traductor un reto diferente y más o menos nuevo en función de una serie inaprensible de variables, entre las que no será la menor el estilo, registro o acento del autor en cuestión: "Cada poeta alcanza, cuando lo alcanzan él y su obra, un idiolecto; de modo que la poesía, más que un género literario, o además, es una constelación de idiolectos" (Ruiz Casanova 2011: 86). De la aptitud lectora del traductor dependerá en gran medida su capacidad de adaptación al poema y sus retos y, por tanto, sus posibilidades de éxito. Traducir poesía es aprender cada vez a traducir poesía.

\section{Algunas propuestas en la enseñanza de la lectura}

A la hora de entrenar en los ejercicios lector y metalector al alumno, con el que habrá que negociar las diferencias entre ambas actividades, cabe considerar cualquier interacción con el texto que implique la elaboración de una o varias interpretaciones por parte del futuro traductor: lecturas colectivas en clase, lecturas guiadas en las que se pide al alumnado localizar y comentar progresivamente los distintos componentes rítmicos, trabajar con las distintas posibilidades de lectura que ofrece un poema (ironía, alegoría, literalismo)... Por nuestra parte, creemos posible trabajar con un corpus textual que permita simultáneamente al alumno conocer las distintas manifestaciones artísticas en ambas lenguas, recorrer la historia poética de ambas culturas en el marco de la poesía universal y fomentar entre los estudiantes el interés por todos aquellos campos científico-artísticos que hayan mantenido históricamente una mayor o menor relación con la poesía y su traducción. Para ello, se antoja imprescindible que ese corpus sea bilingüe: la lengua y la cultura de llegada suelen ser las grandes olvidadas de las guías docentes de las asignaturas de traducción literaria, y parece harto difícil poder escribir un poema en una lengua en la que no hemos leído poesía. En este sentido, la tarea del docente de traducción literaria difiere poco de la del "guía cultural", en la insuperable metáfora de Paola Masseau (2010: 236).

Asimismo, esta contextualización cronológica de la evolución poética en la que se trabaje con textos contemporáneos pertenecientes a las dos tradiciones literarias en liza facilitará la adquisición progresiva de recursos por parte del estudiante, en tanto en cuanto los grandes poetas han ido ampliando los límites de la expresión poética a lo largo de las décadas. Si una asignatura de 6 créditos en la que, además, probablemente no sólo se trabajará con textos poéticos resulta más que insuficiente para profundizar en la tradición literaria de dos culturas (siquiera de una), sí que cabe repasar los principales hitos. Por ejemplo, en el caso de la traducción francésespañol se puede empezar por textos épicos como La Chanson de Roland, las primeras versiones del Tristan et Yseult y los Laïs de Marie de France, a los que puede servir de comparación en nuestra lengua el Cantar de mío Cid, para continuar con los primeros sonetistas en ambas lenguas (petrarquistas y no), con textos que, en 
cualquier caso, se escribían para ser cantados, antes de pasar a los poemas en prosa baudelairianos o la epopeya lautréamontiana, o la explosión de la expresión vanguardista en el s. XX. Una singladura organizada de este tipo dotará al alumno de un panorama diacrónico que le permita tomar conciencia de la intertextualidad, autorreferencialidad y relación de numerosos textos artísticos en ambas lenguas (el origen celta de parte de la leyenda de Tristan et Yseult, por ejemplo) que llevan a muchos críticos a considerar la literatura como un continuo palimpsesto, y dará cuenta de la razón de ser de los distintos ritmos, como las motivaciones mnemotécnicas que llevaban a trovadores y troveros medievales a crear textos en versos de metro regular y rimados, o la importancia de la polisemia y la polifonía en la poesía simbolista del XIX, y la evolución de dichos recursos en el seno de una tradición poética.

Las prácticas de traducción y crítica alrededor de dicho corpus deberían combinarse indefectiblemente con otras de creación y recreación, como puedan ser los pastiches o los ejercicios de escritura potencial o colectiva. A medida que avancen en el estudio y experimentación, se irán liberando -como la poesía- y entenderán, acaso con asombro, que la complejidad de la traducción poética es inversamente proporcional a las limitaciones o restricciones (contraintes) del poema original.

$\mathrm{Al}$ inicio de este artículo hablábamos de las posibilidades de enriquecimiento del traductor de cualquier especialidad a través del aprendizaje de la traducción poética. Algunas de las competencias que pueden potenciarse en el aula de traducción poética/literaria y que a menudo se dejan de lado son la iniciativa, el trabajo en equipo y la capacidad de autoedición. Un buen trabajo final puede consistir en la elaboración de un dossier de propuesta de traducción para una editorial que conste de su correspondiente presentación crítica de la obra, presentación curricular del alumno, factura o propuesta de contrato en base a derechos de autor, etc. De igual modo, autoeditar una revista en la que publicar crítica y traducción poética puede ser una gran idea, sobre todo si se hace en colaboración con alumnos y docentes de otras titulaciones de humanidades (filologías, pero también carreras de historia o filosofía), fomentando así la interacción con otros campos del saber y ampliando los horizontes de unos estudiantes que habrán de acudir a multitud de disciplinas en su futuro profesional; incluso, por qué no, la revista puede registrarse con su propio ISSN para que los alumnos salgan del aula con una referencia en este sentido para su currículum. Dadas las posibilidades gratuitas que Internet ofrece para la autoedición (.pdf, .html, blogs...), los límites a este tipo de actividad los ponen sólo la imaginación y las ganas de trabajar de la comunidad universitaria.

Para finalizar, las carencias teóricas que puede acarrear la pérdida de créditos dedicados a la traducción de literatura y poesía en los grados deberían suplirse a través de una mayor coordinación y consenso entre los docentes de las asignaturas específicas de traducción y los de las materias más generales, como puedan ser Teoría e historia de la traducción -no olvidemos que, hasta la aparición de los estudios de traducción, ya entrado el s. XX, las reflexiones sobre esta actividad orbitaban alrededor de la traducción de textos literarios-, las asignaturas de Traducción general y, en cuanto a la ejercitación en la lectura, las asignaturas de lingüística, de análisis de textos y de lenguas. Sólo de este modo parece plausible, en el actual con- 
texto, que las asignaturas específicas puedan centrar sus esfuerzos teóricos en una mayor profundización en la materia en lugar de quedarse en las nociones básicas, lo que a menudo supone para el alumno un estancamiento en niveles de aprendizaje que pronto se demuestran insuficientes en cualquier práctica extraacadémica.

\section{A modo de conclusión}

La conclusión más nítida a la que nos conduce todo lo anterior es que, si "las ‘competencias' están matando los 'conocimientos'”, como advertía Miguel Ángel Vega en 2007 (p. 95), detener el empobrecimiento formativo al que el nuevo marco europeo de enseñanza parece abocar a los alumnos de Traducción e Interpretación pasa por revalorizar el ejercicio de la traducción poética y devolverlo al conocimiento filológico en su sentido clásico de "suma de saberes humanísticos que permiten la interpretación integral del texto a partir de la interpretación integral del mundo" (Vega 2007: 95). Para vencer las limitaciones que el EEES impone a profesores y alumnos cabe experimentar un cambio de enfoque hacia una enseñanza no cosificada de este tipo de traducción, pero también urge que el profesorado universitario trabaje en pos de una mayor coordinación temática y de objetivos que permita instaurar en nuestras Facultades la mejor formación posible de humanistas, que es, al fin y al cabo, lo que en última instancia son los traductores. Y esto, por más que la medicina forense universitaria haya certificado en numerosas ocasiones la muerte del Humanismo. Por más que habitemos un mundo, que nos habite un mundo donde la inteligencia es una cualidad aplicable a una bomba. Porque creemos ingenua y firmemente que mientras quede en nuestras aulas un rincón para la poesía quedará para nuestros alumnos un pedazo de futuro.

\section{Referencias bibliográficas}

Alonso, D., Poesía española: Ensayo de métodos y límites estilísticos. Madrid: Gredos 1981 (1 $1^{\mathrm{a}}$ edición: 1966).

ARregui, N., «La didáctica de la traducción literaria: un caso práctico en alumnos de doctorado de Granada», en: Albaladejo Martínez, J. A. / Gallego Hernández, D. / ToloSA IGUALADA, M. (eds.), La didáctica de la traducción en Europa e Hispanoamérica. Alicante: Departamento de Traducción e Interpretación 2007, 149-159.

Dessons, G. / Meschonnic, H., Traité du rythme des vers et des proses. París: Nathan 1998. Eagleton, T., Cómo leer un poema. Traducción de Mario Jurado. Madrid: Akal 2010.

EsPitallier, J.-M., Caisse à outils: Un panorama de la poésie française aujourd'hui. París: Pocket 2006.

Gallego RocA, M., Traducción y literatura: Los estudios literarios ante las obras traducidas. Madrid: Ediciones Júcar 1994.

Hurtado Albir, A., Enseñar a traducir: teoría y fichas prácticas. Madrid: Edelsa 1999.

Ivo, L., La aldea de sal. Selección y traducción de Guadalupe Grande y Juan Carlos Mestre. Madrid: Calambur 2009. 
Marco Borillo, J. / Verdegal Cerezo, J. M. / Hurtado Albir, A., «La traducción literaria», en: HurTado AlbiR, A. (ed.), Enseñar a traducir. Madrid: Edelsa 1999, Colección Investigación Didáctica, 167-181.

MASSEAU, P., «¿Son compatibles el aula y la traducción de poesía? Descripción de una práctica metodológica en el aula de traducción poética», en: BlANCO GARCÍA, P. (ed.), El Cid y la Guerra de la independencia: dos hitos en la Historia de la Traducción y la Literatura. Madrid: Instituto Universitario de Lenguas Modernas y Traductores 2010, 235-245.

MoYA, V., La selva de la traducción: teorías traductológicas contemporáneas. Madrid: Cátedra 2004.

Murphy, S., Logiques du dernier Baudelaire: Lectures du Spleen de Paris. París: Honoré Champion 2007.

PINO, M., «¿Se puede enseñar a traducir?», Vasos comunicantes 29 (2004), 23-35.

ReISS, K. / Vermeer, H. J., Fundamentos para una teoría funcional de la traducción. Traducción de Sandra García Reine y Celia Martín de León; coordinación de Heidrun Witte. Madrid: Akal 1996 ( $1^{\mathrm{a}}$ edición alemana: 1991).

Ruiz Casanova, J. F., Dos cuestiones de literatura comparada: traducción y poesía. Exilio y traducción. Madrid: Cátedra 2011.

Santoyo, J. C., Teoría y crítica de la traducción: Antología. Bellaterra (Barcelona): Servei de publicacions de la Universitat Autònoma de Barcelona 1987.

Vega Cernuda, M. Á., Textos clásicos de teoría de la traducción. Madrid: Cátedra 1994.

VEga CERnUdA, M. Á., «El ordenador de san Jerónimo o los retos del futuro en la enseñanza de la traducción», en: Navarro Domínguez, F. / Vega Cernuda, M. Á. / Albaladejo Martínez, J. A. / Gallego Hernández, D. / Tolosa Igualada, M. (eds.), La traducción: balance del pasado y retos del futuro. Alicante: Aguaclara 2007, 87-97.

Verdegal Cerezo, J. M., «La enseñanza de la traducción literaria», en: HurTAdo Albir, A. (ed.), La enseñanza de la traducción. Castellón: Universitat Jaume I 1996, 213-216. 